\title{
Orbital sparganosis in an 8-year boy: a case report
}

\author{
Xin Xie ${ }^{1}$, Jianghua Hu${ }^{1}$, Guizhen Sun², Bo Ding ${ }^{3}$ and Lei Feng ${ }^{1 *}$
}

\begin{abstract}
Background: Sparganosis is one of the neglected but important food-borne parasitic zoonoses, with higher prevalence in Asian countries. The infection is commonly located in the subcutaneous tissue, brain, breast, and lung, but fewer reported infections involve the eye. Because the majority of patients with sparganosis are adults, it is likely to be missed in children.

Case presentation: An 8-year-old boy presented to our clinic complaining of a painless ocular mass in his right eye for 1 month. The boy had a history of eating frogs and frog poultice applications to his eyelids. The patient was checked for an elliptical mass near the medial wall of the right eye. Serodiagnosis testing was positive in an enzyme-linked immunosorbent assay. During surgical operation on the patient, calcified parasite eggs and foreign body granulomatous reaction were found using histological examination. Due to early detection and surgery, the patient fully recovered with no damage to his eyesight.

Conclusions: Although rare, ocular sparganosis should be suspected in a mass of the eye when there is a history of eating frogs and frog poultice applications on eyelids. Early surgical resection is important for a good prognosis.
\end{abstract}

Keywords: Sparganosis, Orbit, Child

\section{Background}

Sparganosis is a zoonotic parasitic infection caused by migrating plerocercoid tapeworm larvae (sparganum) of the genus Spirometra [1]. Athough it has been reported sporadically around the world, a higher prevalence of this disease occurs in Asian countries [2]. The infection is commonly located in the subcutaneous tissue, brain, breast, and lung, but fewer reported infections involve the eye [3].

Because the majority of patients with sparganosis are adults, it is likely to be missed in children [4]. Larvae may develop inside a patient's eyes, progressively impairing patient vision if not treated immediately. In this report, we present a case of orbit sparganosis in an 8-yearold boy.

\footnotetext{
* Correspondence: leifeng@zju.edu.cn

${ }^{1}$ Eye Center, the Second Affiliated Hospital, School of Medicine, Zhejiang University, No. 88 Jiefang Road, Hangzhou 310009, People's Republic of China

Full list of author information is available at the end of the article
}

\section{Case presentation}

An 8-year-old boy of Han nationality from the Zhejiang province in China presented to our clinic complaining of having a painless ocular mass in his right eye for 1 month without any medical treatment. Ophthalmological examinations revealed that the anterior orbital tumor was approximately $0.5 \times 0.8 \mathrm{~cm}$ in size in the right eye. The tumor could be touched and moved under the skin with palpation. Computed tomography (CT) examination showed that the tumor was localized in the intraorbital soft tissue near the medial wall (Fig. 1a). Examinations showed that the boy's left eye was normal. The visual acuity of both eyes was $20 / 20$, and his intraocular structure and his ocular motility were normal before operation. With laboratory tests, blood cell count was determined to be $5800 / \mathrm{cmm}$, and the eosinophil percentage was $2.7 \%$. Renal and liver function tests were normal. Electrocardiogram (ECG) and X-ray imaging for the heart and lungs also showed normal readings.

The patient reported that he had eaten frogs and applied frog poultice to his eyelids many times since he was 4 years old. The suspicious diagnosis of orbit sparganosis was 


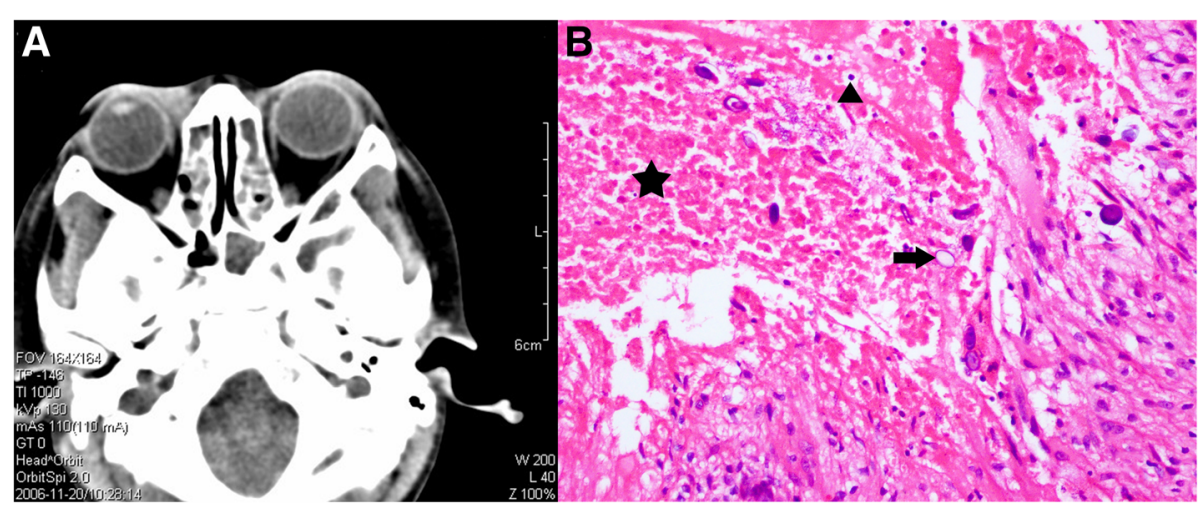

Fig. 1 a. the results of computed tomography examination of the orbit; b. Histologic examination showed necrosis(a black pentagram), Inflammatory cells (a black triangle) and basophilic calcified eggs (a black arrow) (Stain, hematoxylin \& eosin, magnifications $\times 200$ )

made considering this special lifestyle habit, and the boy was advised by the clinic to have further serological tests. An enzyme-linked immunosorbent assay (ELISA) tested positive for the specific IgG antibody of sparganosis in the serum of the boy. An operation was then performed. After tumor excision, histopathologic examinations showed granulomatous inflammation, necrosis, and basophilic calcified eggs (Fig. 1b). Tests for acid-fast staining, periodic acid-schiff staining, and periodic acid-silver metheramine staining were negative.

Based on the presence of calcified eggs and patient history, we confirmed the diagnosis of ocular sparganosis. Visual acuity of the patient remained 20/20 and ocular motility was not restricted after the operation.

\section{Discussion}

Sparganosis is a serious food-borne parasitic zoonosis that is not of high concern due to its rare prevalence. This disease is caused by larvae infection of the Spirometra species. Adult Spirometra cestodes live in the small intestine of carnivores. They release eggs with host faeces to contaminate the environment. The miracidia hatch from the eggs to find a suitable intermediate host. In nature, frogs act as the main secondary intermediate hosts [5]. Humans are dead-end hosts for this parasite, infected by two primary methods: ingestion of uncooked meat of secondary intermediate hosts and ingestion of impure water contaminated with copepods [6]. Sparganosis can parasitize anywhere in the human body, such as the breast, brain, and lungs [7-9]. Li et al. reported that ocular sparganosis accounted for only $12.8 \%$ of all cases of sparganosis [10]. Human orbital tissues or the ocular globe may be infected by Spirometra at the adult or larval stages. Structures affected may include the eyelids, conjunctival sacs, subconjunctiva, lachrymal glands, anterior chamber, and other areas (such as retina). Immune reactions may also be caused by
Spirometra parasites in the eye. Ocular alterations or antibody-mediated reactions caused by this parasite can result in mild to severe clinical symptoms, including lacrimation, conjunctivitis, retinal lesions, and orbital tumors, resulting in structure or vision damage [11]. However, sparganosis in the children's eyes is a kind of relatively rare event. Although the majority of patients with sparganosis are adults, we shouldn't neglect the possibility of this disease occurring among the children who couldn't accurately express their discomfort and have the risky habits associated with the routes of parasitic infection. The patient in this study was only 8 years old and appeared to have been infected by frog consumption or frog poultice applications.

The diagnosis of sparganosis in this case was based on imaging, immunologic examination, and pathologic results. Chen et al. reported that cerebral sparganosis presented low and high density lesions on CT images and a ring or a beaded enhancement on enhanced magnetic resonance (MR) or CT images [12]. Immunologic examination is very helpful when the diagnosis is in doubt. The ELISA test has widely been used because of its high sensitivity [13]. A definitive diagnosis can be made by surgical pathologic inspections. In this case, due to early detection and surgery, the patient recovered well and had no eyesight damage. Therefore, we suggest that sparganosis should be suspected in an ocular mass unresponsive to medical treatment.

Surgical removal is the most effective for proliferative sparganosis [14]. But considering the recurrence which is caused by an epibiotic scolex, it is worth mentioning that drugs such as praziquantel and mebendazole should be used for systemic infection of Sparganosis [15]. What's more, high-dose praziquantel can be used for inoperable cases of sparganosis, such as eosinophilic pleural effusion caused by Sparganum [16] or cerebral sparganosis [17]. 


\section{Conclusion}

Although rare, ocular sparganosis should be suspected in a mass of the eye with a special history. Early detection and treatment is important for a good prognosis.

\section{Additional file}

Additional file 1: Case report guidelines. (PDF $871 \mathrm{~kb}$ )

\section{Acknowledgements}

The authors thank the patient and his family for their intensive cooperation and participation in this study.

\section{Funding}

This work was supported by the National Natural Science Foundation of China (81500760, Beijing, PR China), the Traditional Chinese Medicine Project of Zhejiang Province (2015ZB032), and the Health Science and Technology Project of Zhejiang Province (2015YB162).

Availability of data and materials

All the data supporting the findings is contained within the manuscript.

\section{Case report guidelines}

This case report was written following CARE guidelines and includes all applicable items on the Additional file 1: CARE checklist.

\section{Authors' contributions}

$X X$ and $\mathrm{HJH}$ was a major contributor in writing the manuscript. GS and BD contributed to the literature search and preparation of the manuscript and figures. LF was responsible for the design of the case report. All authors read and approved the final manuscript.

\section{Ethics approval and consent to participate}

Ethical approval was not required as this manuscript presents a case study. It was performed in accordance with the tenets of the Declaration of Helsinki.

\section{Consent for publication}

We confirmed that patient and his parents had seen the manuscript and patient data and agreed to its publication in a journal. Written informed consents were obtained from the patient for publication of this case report and any accompanying images. A copy of the consents is available for review by the Editor of this journal.

\section{Competing interests}

The authors declare that they have no competing interests.

\section{Publisher's Note}

Springer Nature remains neutral with regard to jurisdictional claims in published maps and institutional affiliations.

\section{Author details}

${ }^{1}$ Eye Center, the Second Affiliated Hospital, School of Medicine, Zhejiang University, No. 88 Jiefang Road, Hangzhou 310009, People's Republic of China. ${ }^{2}$ Department of ophthalmology, Naval Convalescent Zone, Hangzhou Sanatorim, Hangzhou, China. ${ }^{3}$ Department of ophthalmology, Hangzhou Sanatorium of Nanjing Command, Hangzhou, China.

Received: 17 January 2017 Accepted: 9 January 2018

Published online: 22 January 2018

\section{References}

1. Anantaphruti MT, Nawa Y, Vanvanitchai Y. Human sparganosis in Thailand: an overview. Acta Trop. 2011;118:171-6.

2. Wiwanitkit V. A review of human sparganosis in Thailand. Int J Infect Dis 2005:9:312-6

3. Ho TH, Lin MC, Yu WW, et al. Ocular sparganosis mimicking an orbital idiopathic inflammatory syndrome. Orbit (Amsterdam,Netherlands). 2013;32: $395-8$.
4. Gong CG, Liao WG, Chineah A, Wang X-Y, Hou Bob L. Cerebral sparganosis in children: epidemiological, clinical and MR imaging characteristics. BMC Pediatr. 2012;12:155

5. Mueller JF. The biology of Spirometra. J Parasito. 1974:60:3-14.

6. Otranto D, Eberhard ML. Zoonotic helminths affecting the human eye. Parasit Vectors. 2011:4:41.

7. Kim WY, Woo SU, Son GS, Lee JB, Bae JW. Breast sparganosis. Breast J. 2013; 19:208-9

8. Pittella JE. Pathology of CNS parasitic infections. Handb Clin Neuro. 2013; 114:65-88.

9. Iwatani K, Kubota I, Hirotsu Y, et al. Sparganum mansoni parasitic infection in the lung showing a nodule. Pathol Int. 2006;56:674-7.

10. Li MW, Song HQ, Li C, et al. Sparganosis in mainland China. Int J Infect Dis. 2011;15:154-6.

11. Yang JW, Lee JH, Kang MS. A case of ocular sparganosis in Korea. Korean Ophthalmol. 2007;21:48-50.

12. Chen $H$, Wu JS, Zhou LF, et al. The diagnosis and treatment of cerebral Sparganosis. Chin J Clinical Neurosci. 2003;11:166-9.

13. Yeo IS, Yong TS, Im K. Serodiagnosis of human sparganosis by a monoclonal antibody-based competition ELISA. Yonsei Med J. 1994;35:43-8.

14. Liu Q, Li MW, Wang ZD, et al. Human sparganosis, a neglected food borne zoonosis. Lancet Infect Dis. 2015;15:1226-5.

15. Li N, Xiang Y, Feng $Y$, et al. Clinical features of pulmonary Sparganosis. Am J Med Sci. 2015;350:436-41.

16. Lin Q, Ouyang JS, Li JM, et al. Eosinophilic pleural effusion due to Spirometra mansoni spargana: a case report and review of the literature. Int J Infect Dis. 2015;34:96-8.

17. Gonzenbach RR, Kong Y, Beck B, et al. High-dose praziquantel therapy for cerebral sparganosis. J Neurol. 2013;260:1423-5.
Submit your next manuscript to BioMed Central and we will help you at every step:

- We accept pre-submission inquiries

- Our selector tool helps you to find the most relevant journal

- We provide round the clock customer support

- Convenient online submission

- Thorough peer review

- Inclusion in PubMed and all major indexing services

- Maximum visibility for your research

Submit your manuscript at www.biomedcentral.com/submit
Biomed Central 